\title{
What we can learn from animal models about cerebral multi-morbidity
}

\author{
Siân Baker and Jürgen Götz
}

\begin{abstract}
Late-onset diseases such as Alzheimer's disease, Parkinson's disease, or frontotemporal lobar degeneration are considered to be protein-folding disorders, with the accumulation of protein deposits causing a gain-of-toxic function. Alzheimer's disease is characterized by two histological hallmark lesions: amyloid- $\beta$-containing plaques and tau-containing neurofibrillary tangles. However, signature proteins, including a-synuclein, which are found in an aggregated fibrillar form in the Lewy bodies of Parkinson's disease brains, are also frequently found in Alzheimer's disease. This highlights the fact that, although specific aggregates form the basis for diagnosis, there is a high prevalence of clinical overlap between neuropathological lesions linked to different diseases, a finding known as cerebral co- or multi-morbidity. Furthermore, the proteins forming these lesions interact, and this interaction accelerates an ongoing degenerative process. Here, we review the contribution that transgenic animal models have made to a better mechanistic understanding of the causes and consequences of co- or multi-morbidity. We discuss selected vertebrate and invertebrate models as well as the insight gained from non-transgenic senescence-accelerated mouse-prone mice. This article is part of a series on 'Cerebral multi-morbidity of the aging brain'.
\end{abstract}

\section{Introduction}

A unifying feature of the pathology of neurodegenerative diseases is the accumulation of misfolded proteins that form insoluble aggregates in both the intra- and extracellular space of the central nervous system. Traditionally, the pathological classification of neurodegenerative diseases has been based on the principal proteins that are present in these aggregates and their localization to distinct brain areas. However, it is rare for the deposited proteins to be unique to one disease. In reality, although specific aggregates form the basis for diagnosis, there is a high prevalence of clinical overlap between neuropathological lesions linked to different diseases, a finding known as cerebral co- or multi-morbidity [1]. Clinical and neuropathological findings are discussed in detail in the articles that accompany our review as part of a series on 'Cerebral multi-morbidity of the aging brain'. Here, we focus on the insight provided by animal models.

Of all the dementias, Alzheimer's disease (AD) is the most prevalent, accounting for approximately two thirds of all cases. Neuropathologically, in addition to neuron

\footnotetext{
* Correspondence: j.goetz@uq.edu.au

Clem Jones Centre for Aging Dementia Research, Queensland Brain Institute, The University of Queensland, Upland Road, Building 79, St Lucia Campus,
} Brisbane, QLD 4072, Australia and synapse loss, the disease is characterized by the presence of amyloid- $\beta$ (A $\beta$ )-containing plaques-with $A \beta$ being proteolytically derived from the larger amyloid precursor protein (APP) - as well as tau-containing neurofibrillary tangles (NFTs) and neuropil threads. It is, however, becoming increasingly clear that these lesions often coexist with other forms of protein aggregates. In fact, about two thirds of aged human AD brains contain additional non-AD pathologies [2-6]. These include protein aggregates of $\alpha$-synuclein, a defining feature of Parkinson's disease (PD) and dementia with Lewy bodies (DLB), as well as transactive response DNA-binding protein $43 \mathrm{kDa}$ (TDP-43) that forms aggregates in subtypes of frontotemporal lobar degeneration (FTLD) and amyotrophic lateral sclerosis (ALS), the latter also known as motor neuron disease $[7,8]$.

Age is the most important risk factor for AD. On the one hand, the hypothesis has been formulated that $\mathrm{AD}$ is an inevitable manifestation of senescence in that the disease, with its neuropathological signatures, is considered a normal phenomenon of aging [9]. On the other hand, the pattern of neuronal loss was shown to differ between normal aging and $\mathrm{AD}$, suggesting that the latter is not an inevitable consequence of the former [10]. Interestingly, however, a recent study indicates that much of 
late-life cognitive decline $(60 \%)$ is not due to common neurodegenerative pathologies such as plaques and NFTs, suggesting that other important determinants are still to be identified [11].

In animals, age-related cognitive impairment or even an AD-like pathology is seen in species that reach an advanced age. In fact, all non-human primate species examined to date have been shown to display NFTs, or A $\beta$ plaques, or both [12,13] (and references therein). Further studies in these species are warranted. Plaques have been reported in the brains of cetaceans (such as whales), birds, fish, carnivorans (such as bears), and ungulates, and NFTs have been reported in the latter two groups [14].

\section{Modelling plaques and neurofibrillary tangles in animals}

Unfortunately, most of the above species are not easily amenable to experimental manipulation, and the animal species traditionally used in laboratory settings, such as mice, flies, or worms, do not naturally develop the protein aggregates seen in $\mathrm{AD}$, in part because of their relatively short life span [14]. Nonetheless, these species have been successfully developed into experimental animal models for $\mathrm{AD}$ by expressing pathogenic mutations that are found in the genes encoding APP, presenilin-1, and presenilin-2 in familial early-onset $A D$ as well as by expressing pathogenic mutations in the tau-encoding $M A P T$ (microtubule-associated protein tau) gene found in familial cases of FTLD (FTDP-17t) [15].

It took several attempts for the research community to succeed in reproducing the end-stage lesions of $\mathrm{AD}$, NFTs and plaques in transgenic mouse models [15]. The discovery of pathogenic mutations, such as those in the $A P P$ and $M A P T$ genes, together with the use of stronger promoters and inducible systems, made possible the reproduction of plaques and NFTs at reasonable numbers and at a reasonable age. Overexpression of wild-type forms of human tau did not reproduce NFTs [16-19] unless the mice reached a high age [20]. Similarly, crossing wild-type human tau transgenic mice with mice carrying the Osaka mutation in APP (E693 $\Delta$ ) resulted in NFT formation at only 18 months of age [21]. However, expression of FTDP-17t mutant forms of tau resulted in a much earlier onset of NFT formation $[22,23]$, and by using an inducible system for transgene expression, the initiation of massive NFT formation has been achieved as early as 2.5 months of age [24].

Small-animal models such as the fruit fly Drosophila melanogaster and the roundworm Caenorhabditis elegans are useful tools for investigating human disorders, as the genes implicated in human disease have homologues in the invertebrates and because many signalling pathways are conserved. For a review of the currently available models of neurodegeneration in C. elegans, see [25]. An advantage of C. elegans lies in the fact that the biological function of, for example, the tau homologue Ptl-1 can be studied without the complication of functional redundancy that is observed in mammals (where tau, MAP2, and MAP4 have partly overlapping functions) [26]. In Drosophila, the expression of human wild-type and mutant forms of proteins with a role in AD, PD, and FTLD has advanced our understanding of the role of these proteins under physiological and pathological conditions. Examples of such models are $\alpha$-synuclein or tau transgenic flies $[27,28]$.

Interestingly, work in the roundworm C. elegans has shown that the expression of both normal and FTDP$17 \mathrm{t}$ mutant tau results in neurodegeneration and defective neurotransmission but that the pathology is more severe in the latter [29]. One of the key advantages of the C. elegans system is the possibility of rapid and comparably cheap modifier screens; this has led, for example, to the identification of sut-2 as being required for tau neurotoxicity [30]. Earlier work in Drosophila had shown that tau-dependent neurodegeneration can occur in the absence of NFT formation [28] and that neuronal expression of wild-type tau in the absence of mutations can cause learning and memory deficits [31]. Several studies have addressed the individual roles of distinct phosphorylation sites of tau, rather than hyperphosphorylation per se, but more studies are required to pinpoint the role of specific tau phosphorylation events and tau isoforms in disease [32,33]. Importantly, highly phosphorylated tau firstly exhibits significantly reduced binding to microtubules and secondly participates in a pathogenic interaction with normal tau, sequestering it away from microtubules [34].

Studies in invertebrates and vertebrates have collectively identified several modes of tau and $A \beta$ dysfunction and how this results in neurodegeneration $[35,36]$. Despite the insight into pathomechanisms provided by these models, transgenic approaches have met with criticism because of (i) unphysiologically high protein levels that are caused, for example, by the integration of multiple transgene copies into the genome, (ii) an altered brain area specificity and subcellular expression pattern of the transgene compared with the endogenous gene because of the use of an exogenous promoter, and (iii) disruption or alteration of endogenous gene expression because of insertion of the transgene into the host genome. Consequently, several groups have pursued alternative strategies. For example, more recently, a knock-in approach was used to introduce the P301L mutation of tau into the murine MAPT locus. Although these mice failed to develop a mature tau pathology [37], this does not preclude their use in dissecting early pathomechanisms, and it is possible, with the advent of new gene-editing methods, that these models can be further refined [38]. 
Additional approaches have exploited mice, such as the senescence-accelerated SAMP (senescence-accelerated mouse-prone) strain, that are characterized by accelerated aging [39]. Together with a series of related senescenceaccelerated mice, the SAMP strains were established 40 years ago by conventional inbreeding of AKR/J-derived mice that displayed features of accelerated aging such as hair loss, reduced activity, shortened life expectancy, lordokyphosis (increased curvature of the spine), and periophthalmic problems [40]. Littermates of mice that did not show a senescence-associated phenotype were also inbred to generate senescence-resistant, longer-lived senescence-accelerated mouse resistant (SAMR) mice, of which the SAMR1 strain is commercially available. SAMP strains exhibit an early onset of age-related decline in their immune system such as thymic involution, loss of $\mathrm{CD}^{+} \mathrm{T}$ cells, impaired helper T-cell function, decreased antibody-forming capacity, dysfunction of antigen-presenting cells, decreased natural killer activity, increased auto-antibodies, and increased susceptibility to viral infection [41].

SAMP8 is the strain that has been most extensively analyzed in relation to cognitive functions [42]. These mice are neuropathologically characterized by oxidative changes similar to those found in the $\mathrm{AD}$ brain [43]. Furthermore, they have an impaired glucose metabolism [44] and exhibit age-dependent reductions in various receptors, including the NMDA receptor [45]. Tau was found to be pathologically phosphorylated in this strain, but filament formation and NFT formation have not been reported, indicating that the SAMP8 mice present with an early tau pathology [46]. Staining with $A \beta$-specific antibodies suggested $A \beta$ deposition in these mice $[47,48]$; however, unlike the human sequence for the $A \beta$ precursor protein APP, the murine protein lacks the amino acids that are required to generate $A \beta$, and as a result these deposits have been termed 'A $\beta$-like' [47]. A more recent study reported the presence of $A \beta$ granules in the hippocampus, which contained also tau but not $\alpha$-synuclein [49]. Another study demonstrated elevated $\alpha$-synuclein levels in SAMP8 mice compared with senescence-resistant SAMR1 mice, but aggregation of neither tau nor $\alpha-$ synuclein was reported in these animals [50]. Together, these findings limit the use of non-transgenic models such as the SAMP mice to study multi-morbidity, in part because authentic end-stage lesions do not form.

\section{Comorbidity addressed in animal models}

$\mathrm{AD}$ and $\mathrm{PD}$ are associated with the cerebral accumulation of $A \beta /$ tau and $\alpha$-synuclein, respectively. Because many patients have clinical and pathological features of both diseases, this raises several possibilities: (i) the pathogenetic pathways overlap; (ii) the presence of one pathologically altered protein (be it in its post-translational modified form or be it present as oligomer, fibril, or microscopically visible aggregate) causes pathological changes to a protein implicated in the other disease, which also includes the formation of mixed aggregates; and finally (iii) synergistic effects exist of $A \beta$ and $\alpha$-synuclein with regard to downstream toxicity (Figure 1).

Several in vitro studies have shown that these particular proteins cross-talk and cause each other's aggregation. For example, $A \beta$ and $\alpha$-synuclein can form dimers that dock on the plasma membrane and then incorporate additional $\alpha$-synuclein molecules, leading to the formation of more stable pentamers and hexamers that adopt a ring-like structure, causing increased calcium influx [51]. These interactions can result in oxidative stress, lysosomal leakage, and mitochondrial dysfunction, as has been discussed in detail by Crews and colleagues [52]. These authors suggested that hybrid molecules of $\mathrm{A} \beta$ and $\alpha$-synuclein might embed not only in the plasma membrane but also in membranes of mitochondria and lysosomes, where they would form nanopore-like structures, which result in abnormal ion conductance. A recent study with implications for DLB showed that the metabotropic glutamate receptor mGluR5 has a role in mediating $A \beta$ oligomer toxicity in hippocampal neurons and that the accumulation of $\alpha$-synuclein fragments makes these cells more vulnerable [53].

We will now discuss how $\alpha$-synuclein interacts with tau $/ A \beta$ in vivo and how this knowledge informs our understanding of comorbidity in AD. In 1993, $\alpha$-synuclein was identified as the non- $\mathrm{A} \beta$ component of $\mathrm{AD}$ amyloid [54], and subsequently a plaque-associated $\alpha$-synuclein pathology was reported in aged amyloid-depositing mutant APP transgenic $\operatorname{Tg} 2576$ mice [55]. Although there was limited tau pathology, the mice displayed frequent neurites that were both ubiquitin- and $\alpha$-synuclein-positive. When mutant APP transgenic mice were crossed with $\alpha$-synuclein overexpressing mice, $\alpha$-synuclein oligomer formation was significantly increased in the doubletransgenic animals [56]. The mice had severe deficits in learning and memory, developed motor deficits earlier than $\alpha$-synuclein single-transgenic mice, and showed prominent age-dependent degeneration of cholinergic neurons and presynaptic terminals. They also had more $\alpha$-synuclein-immunoreactive neuronal inclusions than observed in $\alpha$-synuclein single-transgenic mice. In addition, some of these inclusions were fibrillar in nature, whereas all inclusions in the single-transgenic mice were amorphous. To address not only whether $A \beta$ has an impact on $\alpha$-synuclein pathology but also whether the inverse could be true, the Tg2576 strain was crossed onto an $\alpha$-synuclein knockout background. This resulted in an increased amyloid plaque load, leading the authors to speculate that $\alpha$-synuclein is not involved in the seeding of the plaques but rather that it suppresses the 


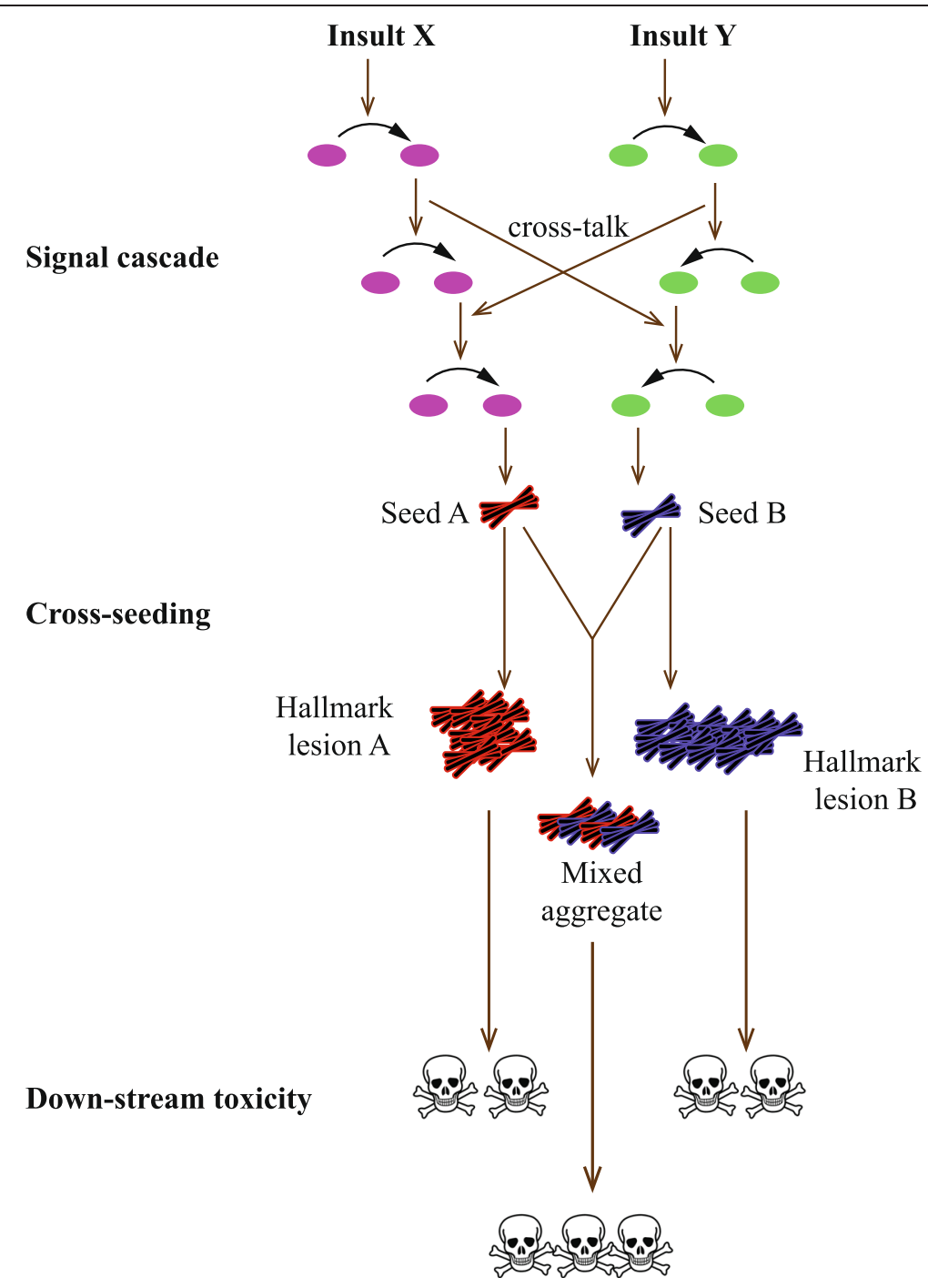

Figure 1 Potential modes of comorbidity. In neurodegenerative disorders there are protein insults considered imperative to the development and characterization of a specific disease (hallmark lesion A) and additional protein pathology that is traditionally classified to another disease state (hallmark lesion B). There are several potential mechanisms by which cross-talk may be occurring between these separate lesions to result in comorbidity: i) at the level of the initial pathogenic signalling cascades which results in the formation of seeds A and B, respectively, (ii) through the ability of one pathological protein (which could range from a post-translational modification state through to a mature aggregate) to induce pathological changes in the state of a protein implicated in another disease, which may also lead to the formation of mixed aggregates, and (iii) a convergence onto mutual cell death pathways.

progression of plaque pathology at advanced stages of the disease [57].

The impact that $\alpha$-synuclein expression has on tau has also been addressed in transgenic mouse models. Giasson and colleagues [58] showed that co-incubation of tau and $\alpha$-synuclein promotes the fibrillization of both proteins. Using negative contrast electron microscopy, they further demonstrated the presence of bundled filaments that were labelled with antibodies for both proteins. They also investigated the formation of tau inclusions in A53T mutant $\alpha$-synuclein transgenic mice and found that, compared with single-transgenic mice, aggregate formation in $\alpha$-synuclein/P301L tau bigenic mice was accelerated by 6 months. Increased hyperphosphorylation of tau was observed in several additional $\alpha$-synuclein transgenic mouse models [59-61], and a study in $\mathrm{E} 46 \mathrm{~K}$ mutant $\alpha$-synuclein transgenic mice revealed that two pathological phospho-epitopes of tau, AT100 and PHF1 (which is a target of several tau immunization studies), were induced by $\alpha$-synuclein [61]. The abundance of tau inclusions in the E46K transgenic mice was greater than observed previously in A53T human $\alpha$-synuclein 
transgenic mice [58]. One of the kinases implicated in $\alpha$-synuclein-mediated tau hyperphosphorylation is glycogen synthase kinase $3 \beta$ (GSK-3 $\beta$ ), one of the major tau kinases. It was shown by co-immunoprecipitation that $\alpha$-synuclein, GSK-3 $\beta$, and tau phosphorylated at the PHF1 epitope pSer396/404 exist as a heterotrimeric complex in human SH-SY5Y neuroblastoma cells [62]. The crosstalk of $\alpha$-synuclein and tau was further addressed in Drosophila, where misexpression of wild-type $\alpha$-synuclein was found to enhance a tau-mediated rough eye phenotype and apoptotic cell death in the eye. Similarly, $\alpha$ synuclein increased tau-dependent abnormal microtubule organization and axonal transport impairment, together with an enhanced tau-induced motor phenotype [63]. Interestingly, the study also found that co-expression of $\alpha$-synuclein and tau led to decreases in synapsin (a synaptic vesicle-associated phosphoprotein) in synaptic boutons, resulting in synaptic apposition defects consistent with synaptic retraction.

Another study addressed the mechanism by which human tau (a strong risk factor for PD) predisposes an individual to PD [64]. This study found that expression of human wild-type tau was sufficient to disrupt the survival of dopaminergic neurons in a Drosophila model and to cause a progressive impairment of motor and learning behaviours. Interestingly, it also demonstrated that, contrary to the common notion that hyperphosphorylated tau aggravates toxicity, the degeneration of dopaminergic neurons was alleviated by expressing a pseudo-hyperphosphorylated form of tau, E14. Several studies used Drosophila to better understand the role of $\mathrm{APP} / \mathrm{A} \beta$ in neurodegeneration $[65,66]$ and more specifically to demonstrate that $A \beta$ exacerbates tau pathology [67].

After the finding that $\mathrm{A} \beta$ toxicity in $\mathrm{AD}$ can be dramatically reduced by removing tau $[68,69]$, whether this holds true for $\alpha$-synuclein was also addressed. However, in two PD models-one pharmacological (by striatal injection of 6-hydroxydopamine) and the other a human wild-type $\alpha$-synuclein transgenic strain-tau reduction did not prevent the motor deficits that characterize these models [70].

To determine how the three key players in $\mathrm{AD} / \mathrm{PD}-$ $\mathrm{A} \beta$, tau, and $\alpha$-synuclein-interact, the A53T mutant $\alpha$-synuclein transgene was introduced into $3 \mathrm{xTg}-\mathrm{AD}$ mice, a strain characterized by both plaque and NFT pathology [71]. As in human disease, the mice developed both DLB and $\mathrm{AD}$ pathologies. Lewy body-like pathology was increased upon co-expression of APP and tau. Tau solubility was decreased and its phosphorylation increased in the crossbred mice, as were levels of detergent-insoluble $A \beta$ (observed for both the $A \beta_{40}$ and $A \beta_{42}$ species). Moreover co-expression of the three proteins accelerated the cognitive decline, with evidence that $\alpha$-synuclein exacerbated cognitive deficits not only in the acquisition of spatial recognition memory but also in the retention of memory. It was further found that accumulation of $\alpha$-synuclein alone could significantly disrupt cognition. A different result was reported in a crossbreed of three strains, A53T $\alpha-$ synuclein mutant mice, Tg2576 and a P264L presenilin-1 knock-in strain that further promotes $A \beta$ plaque formation. Here, despite the accumulation of dystrophic neurites that were positive for hyperphosphorylated $\alpha$-synuclein both within and surrounding $A \beta$ plaques, no additional $\alpha-$ synuclein pathologies were observed. It was concluded that $\mathrm{A} \beta$ deposits can cause the local aggregation of $\alpha$-synuclein but that this does not lead to a more extensive $\alpha$-synuclein pathology [72].

Considering evidence that soluble, non-fibrillar $A \beta$ (and tau) may be the more neurotoxic species, Larson and colleagues [73] assessed the putative role of soluble $\alpha$-synuclein in AD. They first showed that there is an approximately twofold increase in monomeric, intracellular $\alpha$-synuclein in brains from AD patients compared with normal controls and subjects suffering from mild cognitive impairment. This accumulation was found to be independent of Lewy body formation. Interestingly, mRNA levels were also increased approximately twofold in $\mathrm{AD}$ patients compared with controls, suggesting the involvement of imbalanced synuclein gene expression. The level of soluble $\alpha$-synuclein was linked to ADassociated cognitive impairment and was also a good predictor of AD-related impairment. When transgenic mice were analyzed, neither of the two APP mutant lines, $\operatorname{Tg} 2576$ and J20, aged between 1 and 17 months, presented with detectable changes in soluble $\alpha$-synuclein. To test whether expression of human tau is required for the regulation of $\alpha$-synuclein expression, soluble $\alpha$-synuclein protein levels were compared in $\operatorname{Tg} 2576$ mice, P301L tau over-expressing $\mathrm{rTg} 4510$ mice, and $\operatorname{Tg} 2576 \times \mathrm{rTg} 4510$ mice. This revealed an approximately twofold increase in soluble $\alpha$-synuclein at 8 months in $\operatorname{Tg} 2576 \times \operatorname{rTg} 4510$ mice, whereas no obvious changes were found in $\mathrm{rTg} 4510$ mice across all age groups. These findings indicate that a synergism between $\mathrm{A} \beta / \mathrm{APP}$ and human tau is required to upregulate $\alpha$-synuclein expression levels.

An exciting study published in 2013 revealed distinct $\alpha$-synuclein strains that differentially promote tau inclusions in neurons [74]. Based on the use of exogenous pre-formed fibrils (termed 'pffs') of $\alpha$-synuclein, two strains (A and B) were generated with a differential ability to cross-seed tau aggregation in cultured neurons. Furthermore, stereotaxic injections of the hippocampus of P301S mutant tau transgenic PS19 mice revealed that differential cross-seeding occurs in vivo. At 3 months post-injection, only rare cells showed abnormal accumulation of hyperphosphorylated tau, recognized by the AT8 antibody near the injection site of strain A-inoculated mice, whereas numerous neurons bearing AT8-positive 
tau inclusions were observed in strain B-injected mice around the same area. Moreover, strain B-injected mice not only displayed significantly more tau inclusions throughout the hippocampus, including regions that were more rostral and caudal to the injection site, but also consistently showed phospho-tau aggregates in the contralateral hippocampus and even the locus coeruleus, a brainstem structure distant from the injection site, indicating the presence of transmission of tau pathology cross-seeded by $\alpha$-synuclein pffs. The differential induction of tau aggregates was further confirmed with a set of antibodies to detect pathological conformations of tau [74].

To date, only a few studies have addressed the effect that other proteins implicated in neurodegeneration have on $A \beta$, tau, and $\alpha$-synuclein. Cross-rescue experiments and co-expression models using TDP-43 and FUS (fused in sarcoma) transgenic flies have provided evidence for a genetic interaction of the two proteins in a common pathway, suggesting a convergence of molecular pathways influencing FTLD (and ALS) pathology [75,76]. It has also been shown that inoculation of the brains of $\alpha$-synuclein transgenic mice with prions $\left(\operatorname{PrP}^{\mathrm{Sc}}\right)$ exacerbates the $\alpha$-synuclein pathology. Remarkably, prion pathology was unmodified by the presence of $\alpha$-synuclein [77]. Of the proteins other than tau that form aggregates in FTLD, TDP-43, and FUS, only TDP-43 has been analyzed in transgenic mouse models of tauopathy [78]. Cytoplasmic accumulation of phosphorylated TDP-43 was specifically found in two tau transgenic models (P301L 0N4R-expressing $\mathrm{rTg} 4510$ mice and JNPL3 mice), but TDP-43 pathology was absent in mouse models of $A \beta$ deposition (TgCRND8, Tg2576, and Tg2576 x P264L PS1 knock-in), $\alpha$-synucleinopathy (A53T-expressing M83 mice and E46K-expressing M47 mice), or Huntington's disease (N586-82Q-C63 model). These data demonstrate that the neurodegenerative cascade associated with a primary tauopathy in tau transgenic mice can also promote TDP-43 abnormalities.

\section{Conclusions}

What are possible explanations for co- or multi-morbidity and what have animal models contributed to a better understanding of this? As it stands, late-onset diseases are mainly protein-folding diseases, with the accumulation of protein deposits causing a gain-of-function proteotoxicity [79]. The concept that has been put forward is that the proteostasis machinery is overwhelmed when there is a chronic elevation of misfolded proteins. Molecular chaperones and other components of the 'clearance machinery' become trapped in the aggregates and this compromises the re-folding of other aggregationprone proteins and facilitates their aggregation [79].
Alternatively, filamentous aggregates that are composed of one protein may directly cross-seed other amyloidogenic proteins because of potentially shared structural features of amyloid fibrils [80]. As has been argued for the interaction of $\alpha$-synuclein and tau, $\alpha$-synuclein might alter the conformation or solubility of tau in brains with tau inclusions, even in the absence of an obvious $\alpha$-synuclein pathology. As only minute amounts of amyloidogenic $\alpha$-synuclein seeds may be required, it is possible that they are undetectable with current methods or, alternatively, are degraded after they initiate tau polymerization [80]. There is strong support for both hypotheses from in vitro experiments as well as the in vivo studies discussed here.

To address whether amyloid deposition associated with $\mathrm{AD}$ perturbs the proteostasis network, $\mathrm{APP}^{\text {swe }} / \mathrm{PS} 1 \mathrm{dE} 9$ transgenic mice with a high amyloid burden were investigated in order to determine whether cytosolic brain proteins would lose their solubility. Using a method that involved detergent extraction and sedimentation coupled with proteomic approaches, this study identified numerous cytosolic proteins that show specific losses in solubility as amyloid accumulates. The identified proteins included glycolytic enzymes as well as members of the 14-3-3 chaperone family. A substantial accumulation of lysine 48-linked polyubiquitin was also detected [81]. Furthermore, a recent study in C. elegans has shown that widespread protein aggregation is an inherent part of aging in worms [82], and by extension this could be assumed to hold true for humans.

The identification of cross-seeding raises the question of whether the neurodegeneration pathways are unique to different diseases or not. Transgenic Drosophila expressing human $\alpha$-synuclein faithfully replicate essential features of human PD, including age-dependent loss of dopaminergic neurons, Lewy-body-like inclusions, and locomotor impairment. To define the transcriptional program involved in $\alpha$-synuclein pathology, the expression of the entire Drosophila genome at pre-symptomatic, early, and advanced disease stages was determined. Fiftyone signature transcripts were tightly associated with $\alpha$-synuclein expression, whereas in age-matched tau transgenic Drosophila, the transcription of $\alpha$-synucleinassociated genes was normal, suggesting highly distinct pathways of neurodegeneration [83]. However, once the aggregates have formed, they have been shown to deregulate similar pathways and protein categories. This is the case even for proteins that aggregate in different organs. In support of this, $A \beta$ and the amyloidogenic protein amylin, which forms aggregates in the pancreas of patients with type 2 diabetes, deregulate the same functional categories in cell culture systems; in fact, these two toxic molecules even show a great overlap in deregulated proteins [84]. 
Together, the findings from animal experimentation and the analysis of human brain tissue support in vitro studies revealing comorbidity in neurodegenerative disease. These studies highlight the involvement of both cross-seeding of the aggregating proteins, synergistic effects in their toxicity, and a vicious cycle of compromised aggregate clearance and protein aggregation.

Note: This article is part of a series on Cerebral multi-morbidity of the aging brain edited by Johannes Attems and Julie Schneider. Other articles in the series can be found at http:// alzres.com/series/cerebral_multimorbidity.

\begin{abstract}
Abbreviations
ON4R: Tau isoform with no amino-terminal insert and four microtubulebinding domains; AD: Alzheimer's disease; ALS: Amyotrophic lateral sclerosis; APP: Amyloid precursor protein; AB: Amyloid- $\beta$; DLB: Dementia with Lewy bodies; FTDP-17t: Frontotemporal dementia linked to the tau gene on chromosome 17; FTLD: Frontotemporal lobar degeneration; FUS: Fused in

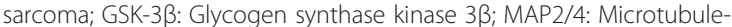
associated protein 2/4; MAPT: Microtubule-associated protein tau; NFT: Neurofibrillary tangle; PD: Parkinson's disease; pff: pre-formed fibril; SAMP: Senescence-accelerated mice prone; SAMR: Senescence-accelerated mouse resistant; TDP-43: Transactive response DNA-binding protein $43 \mathrm{kDa}$.
\end{abstract}

\section{Competing interests}

The authors declare that they have no competing interests.

\section{Acknowledgments}

This study was supported by the Estate of $\mathrm{Dr}$ Clem Jones AO and the State Government of Queensland and by grants from the Australian Research Council (DP13300101932) and the National Health and Medical Research Council of Australia (APP1037746 and APP1003150) to JG.

\section{Published online: 29 January 2015}

\section{References}

1. Attems J, Jellinger K. Neuropathological correlates of cerebral multimorbidity. Curr Alzheimer Res. 2013;10:569-77.

2. Nagy Z, Esiri MM, Jobst KA, Morris JH, King EM, McDonald B, et al. The effects of additional pathology on the cognitive deficit in Alzheimer disease. J Neuropathol Exp Neurol. 1997;56:165-70.

3. Schneider JA, Arvanitakis Z, Bang W, Bennett DA. Mixed brain pathologies account for most dementia cases in community-dwelling older persons. Neurology. 2007;69:2197-204.

4. Nelson PT, Jicha GA, Schmitt FA, Liu H, Davis DG, Mendiondo MS, et al. Clinicopathologic correlations in a large Alzheimer disease center autopsy cohort: neuritic plaques and neurofibrillary tangles "do count" when staging disease severity. J Neuropathol Exp Neurol. 2007:66:1136-46.

5. Jellinger KA, Attems J. Prevalence and pathology of vascular dementia in the oldest-old. J Alzheimers Dis. 2010;21:1283-93.

6. Davidson YS, Raby S, Foulds PG, Robinson A, Thompson JC, Sikkink S, et al. TDP-43 pathological changes in early onset familial and sporadic Alzheimer's disease, late onset Alzheimer's disease and Down's syndrome: association with age, hippocampal sclerosis and clinical phenotype. Acta Neuropathol. 2011:122:703-13.

7. Duyckaerts C, Delatour B, Potier MC. Classification and basic pathology of Alzheimer disease. Acta Neuropathol. 2009;118:5-36.

8. Robinson JL, Geser F, Corrada MM, Berlau DJ, Arnold SE, Lee VM, et al. Neocortical and hippocampal amyloid-beta and tau measures associate with dementia in the oldest-old. Brain. 2011;134:3708-15.

9. Reser JE. Alzheimer's disease and natural cognitive aging may represent adaptive metabolism reduction programs. Behav Brain Funct. 2009;5:13.
10. West MJ, Coleman PD, Flood DG, Troncoso JC. Differences in the pattern of hippocampal neuronal loss in normal aging and Alzheimer's disease. Lancet. 1994;344:769-72.

11. Boyle PA, Wilson RS, Yu L, Barr AM, Honer WG, Schneider JA, et al. Much of late life cognitive decline is not due to common neurodegenerative pathologies. Ann Neurol. 2013;74:478-89.

12. Kimura N, Nakamura S, Goto N, Narushima E, Hara I, Shichiri S, et al. Senile plaques in an aged western lowland gorilla. Exp Anim. 2001;50:77-81.

13. Finch CE, Sapolsky RM. The evolution of Alzheimer disease, the reproductive schedule, and apoE isoforms. Neurobiol Aging. 1999;20:407-28.

14. Glass DJ, Arnold SE. Some evolutionary perspectives on Alzheimer's disease pathogenesis and pathology. Alzheimers Dement. 2012;8:343-51.

15. Götz J, Ittner LM. Animal models of Alzheimer's disease and frontotemporal dementia. Nat Rev Neurosci. 2008;9:532-44.

16. Götz J, Probst A, Spillantini MG, Schafer T, Jakes R, Burki K, et al. Somatodendritic localization and hyperphosphorylation of tau protein in transgenic mice expressing the longest human brain tau isoform. Embo J. 1995;14:1304-13.

17. Spittaels K, Van den Haute C, Van Dorpe J, Bruynseels K, Vandezande K, Laenen I, et al. Prominent axonopathy in the brain and spinal cord of transgenic mice overexpressing four-repeat human tau protein. Am J Pathol. 1999;155:2153-65.

18. Ishihara T, Hong M, Zhang B, Nakagawa Y, Lee MK, Trojanowski JQ, et al. Age-dependent emergence and progression of a tauopathy in transgenic mice overexpressing the shortest human tau isoform. Neuron. 1999;24:751-62.

19. Probst A, Götz J, Wiederhold KH, Tolnay M, Mistl C, Jaton AL, et al. Axonopathy and amyotrophy in mice transgenic for human four-repeat tau protein. Acta Neuropathol (Berl). 2000;99:469-81.

20. Ishihara T, Zhang B, Higuchi M, Yoshiyama Y, Trojanowski JQ, Lee VM. Age-dependent induction of congophilic neurofibrillary tau inclusions in tau transgenic mice. Am J Pathol. 2001;158:555-62.

21. Umeda T, Maekawa S, Kimura T, Takashima A, Tomiyama T, Mori H. Neurofibrillary tangle formation by introducing wild-type human tau into APP transgenic mice. Acta Neuropathol. 2014;127:685-98.

22. Lewis J, McGowan E, Rockwood J, Melrose H, Nacharaju P, Van Slegtenhorst $M$, et al. Neurofibrillary tangles, amyotrophy and progressive motor disturbance in mice expressing mutant (P301L) tau protein. Nat Genet. 2000;25:402-5.

23. Götz J, Chen F, van Dorpe J, Nitsch RM. Formation of neurofibrillary tangles in P301L tau transgenic mice induced by Abeta 42 fibrils. Science. 2001;293:1491-5.

24. Santacruz K, Lewis J, Spires T, Paulson J, Kotilinek L, Ingelsson M, et al. Tau suppression in a neurodegenerative mouse model improves memory function. Science. 2005;309:476-81.

25. Li J, Le W. Modeling neurodegenerative diseases in Caenorhabditis elegans. Exp Neurol. 2013;250:94-103.

26. Chew YL, Fan X, Götz J, Nicholas HR. Protein with tau-like repeats regulates neuronal integrity and lifespan in C. elegans. J Cell Sci. 2013;126:2079-91.

27. Feany MB, Bender WW. A Drosophila model of Parkinson's disease. Nature. 2000;404:394-8.

28. Wittmann CW, Wszolek MF, Shulman JM, Salvaterra PM, Lewis J, Hutton M, et al. Tauopathy in Drosophila: neurodegeneration without neurofibrillary tangles. Science. 2001;293:711-4.

29. Kraemer BC, Zhang B, Leverenz JB, Thomas JH, Trojanowski JQ, Schellenberg $\mathrm{GD}$. From the cover: neurodegeneration and defective neurotransmission in a Caenorhabditis elegans model of tauopathy. Proc Natl Acad Sci U S A. 2003;100:9980-5.

30. Guthrie CR, Schellenberg GD, Kraemer BC. SUT-2 potentiates tau-induced neurotoxicity in Caenorhabditis elegans. Hum Mol Genet. 2009;18:1825-38.

31. Mershin A, Pavlopoulos E, Fitch O, Braden BC, Nanopoulos DV, Skoulakis EM. Learning and memory deficits upon TAU accumulation in Drosophila mushroom body neurons. Learn Mem. 2004;11:277-87.

32. Steinhilb ML, Dias-Santagata D, Fulga TA, Felch DL, Feany MB. Tau phosphorylation sites work in concert to promote neurotoxicity in vivo. Mol Biol Cell. 2007;18:5060-8.

33. Kosmidis S, Grammenoudi S, Papanikolopoulou K, Skoulakis EM. Differentia effects of Tau on the integrity and function of neurons essential for learning in Drosophila. J Neurosci. 2010;30:464-77.

34. Cowan CM, Bossing T, Page A, Shepherd D, Mudher A. Soluble hyperphosphorylated tau causes microtubule breakdown and functionally compromises normal tau in vivo. Acta Neuropathol. 2010;120:593-604. 
35. Frost B, Gotz J, Feany MB. Connecting the dots between tau dysfunction and neurodegeneration. Trends Cell Biol. 2015;25:46-53.

36. Krstic $D$, Knuesel I. Deciphering the mechanism underlying late-onset Alzheimer disease. Nat Rev Neurol. 2013:9:25-34.

37. Gilley J, Seereeram A, Ando K, Mosely S, Andrews S, Kerschensteiner M, et al. Age-dependent axonal transport and locomotor changes and tau hypophosphorylation in a "P301L" tau knockin mouse. Neurobiol Aging. 2012;33:621 e1-621 e15.

38. Gaj T, Gersbach CA, Barbas 3rd CF. ZFN, TALEN, and CRISPR/Cas-based methods for genome engineering. Trends Biotechnol. 2013;31:397-405.

39. Delerue F, Sjollema G, Whittle B, Kruger S, Andrews D, Gotz J. Single nucleotide variants (SNVs) define senescence-accelerated SAMP8 mice, a model of a geriatric condition. J Alzheimers Dis. 2013;36:349-63.

40. Takeda T. Senescence-accelerated mouse (SAM): a biogerontological resource in aging research. Neurobiol Aging. 1999:20:105-10.

41. Shimada A, Hasegawa-Ishii S. Senescence-accelerated mice (SAMs) as a model for brain aging and immunosenescence. Aging Dis. 2011;2:414-35.

42. Flood JF, Morley JE. Learning and memory in the SAMP8 mouse. Neurosci Biobehav Rev. 1998:22:1-20.

43. Schmitt K, Grimm A, Kazmierczak A, Strosznajder JB, Götz J, Eckert A. Insights into mitochondrial dysfunction: aging, amyloid-beta, and tau-A deleterious trio. Antioxid Redox Signal. 2012;16:1456-66.

44. Kurokawa T, Sato E, Inoue A, Ishibashi S. Evidence that glucose metabolism is decreased in the cerebrum of aged female senescence-accelerated mouse; possible involvement of a low hexokinase activity. Neurosci Lett. 1996;214:45-8

45. Kitamura Y, Zhao XH, Ohnuki T, Nomura Y. Ligand-binding characteristics of $[3 \mathrm{H}] \mathrm{QNB},[3 \mathrm{H}]$ prazosin, $[3 \mathrm{H}]$ rauwolscine, $[3 \mathrm{H}] \mathrm{TCP}$ and $[3 \mathrm{H}]$ nitrendipine to cerebral cortical and hippocampal membranes of senescence accelerated mouse. Neurosci Lett. 1989:106:334-8.

46. Canudas AM, Gutierrez-Cuesta J, Rodriguez MI, Acuna-Castroviejo D, Sureda FX, Camins A, et al. Hyperphosphorylation of microtubule-associated protein tau in senescence-accelerated mouse (SAM). Mech Ageing Dev. 2005;126:1300-4

47. Takemura M, Nakamura S, Akiguchi I, Ueno M, Oka N, Ishikawa S, et al. Beta/A4 proteinlike immunoreactive granular structures in the brain of senescence-accelerated mouse. Am J Pathol. 1993;142:1887-97.

48. Fukunari A, Kato A, Sakai Y, Yoshimoto T, Ishiura S, Suzuki K, et al. Colocalization of prolyl endopeptidase and amyloid beta-peptide in brains of senescence-accelerated mouse. Neurosci Lett. 1994:176:201-4.

49. Manich G, Mercader C, del Valle J, Duran-Vilaregut J, Camins A, Pallas M, et al. Characterization of amyloid-beta granules in the hippocampus of SAMP8 mice. J Alzheimers Dis. 2011;25:535-46.

50. Caballero B, Vega-Naredo I, Sierra V, Huidobro-Fernandez C, Soria-Valles C, De Gonzalo-Calvo D, et al. Favorable effects of a prolonged treatment with melatonin on the level of oxidative damage and neurodegeneration in senescence-accelerated mice. J Pineal Res. 2008:45:302-11.

51. Tsigelny IF, Crews L, Desplats P, Shaked GM, Sharikov Y, Mizuno H, et al. Mechanisms of hybrid oligomer formation in the pathogenesis of combined Alzheimer's and Parkinson's diseases. PLoS One. 2008;3:e3135.

52. Crews L, Tsigelny I, Hashimoto M, Masliah E. Role of synucleins in Alzheimer's disease. Neurotox Res. 2009;16:306-17.

53. Overk CR, Cartier A, Shaked G, Rockenstein E, Ubhi K, Spencer B, et al. Hippocampal neuronal cells that accumulate alpha-synuclein fragments are more vulnerable to Abeta oligomer toxicity via mGluR5 - implications for dementia with Lewy bodies. Mol Neurodegener. 2014;9:18.

54. Ueda K, Fukushima H, Masliah E, Xia Y, Iwai A, Yoshimoto M, et al. Molecular cloning of CDNA encoding an unrecognized component of amyloid in Alzheimer disease. Proc Natl Acad Sci U S A. 1993;90:11282-6.

55. Yang F, Ueda K, Chen P, Ashe KH, Cole GM. Plaque-associated alpha-synuclein (NACP) pathology in aged transgenic mice expressing amyloid precursor protein. Brain Res. 2000;853:381-3.

56. Masliah E, Rockenstein E, Veinbergs I, Sagara Y, Mallory M, Hashimoto M, et al. beta-Amyloid peptides enhance alpha-synuclein accumulation and neuronal deficits in a transgenic mouse model linking Alzheimer's disease and Parkinson's disease. Proc Natl Acad Sci U S A. 2001;98:12245-50.

57. Kallhoff $V$, Peethumnongsin $E$, Zheng $H$. Lack of alpha-synuclein increases amyloid plaque accumulation in a transgenic mouse model of Alzheimer's disease. Mol Neurodegener. 2007;2:6.
58. Giasson Bl, Forman MS, Higuchi M, Golbe LI, Graves CL, Kotzbauer PT, et al. Initiation and synergistic fibrillization of tau and alpha-synuclein. Science. 2003;300:636-40.

59. Frasier M, Walzer M, McCarthy L, Magnuson D, Lee JM, Haas C, et al. Tau phosphorylation increases in symptomatic mice overexpressing A30P alpha-synuclein. Exp Neurol. 2005:192:274-87.

60. Haggerty T, Credle J, Rodriguez O, Wills J, Oaks AW, Masliah E, et al. Hyperphosphorylated Tau in an alpha-synuclein-overexpressing transgenic model of Parkinson's disease. Eur J Neurosci. 2011;33:1598-610.

61. Emmer KL, Waxman EA, Covy JP, Giasson BI. E46K human alpha-synuclein transgenic mice develop Lewy-like and tau pathology associated with age-dependent, detrimental motor impairment. J Biol Chem. 2011;286:35104-18.

62. Duka T, Duka V, Joyce JN, Sidhu A. Alpha-Synuclein contributes to GSK-3beta-catalyzed Tau phosphorylation in Parkinson's disease models. FASEB J. 2009;23:2820-30.

63. Roy B, Jackson GR. Interactions between Tau and alpha-synuclein augment neurotoxicity in a Drosophila model of Parkinson's disease. Hum Mol Genet. 2014;23:3008-23.

64. Wu TH, Lu YN, Chuang CL, Wu CL, Chiang AS, Krantz DE, et al. Loss of vesicular dopamine release precedes tauopathy in degenerative dopaminergic neurons in a Drosophila model expressing human tau. Acta Neuropathol. 2013;125:711-25.

65. Gunawardena S, Goldstein LS. Disruption of axonal transport and neuronal viability by amyloid precursor protein mutations in Drosophila. Neuron. 2001;32:389-401.

66. Greeve I, Kretzschmar D, Tschape JA, Beyn A, Brellinger C, Schweizer M, et al. Age-dependent neurodegeneration and Alzheimer-amyloid plaque formation in transgenic Drosophila. J Neurosci. 2004;24:3899-906.

67. Folwell J, Cowan CM, Ubhi KK, Shiabh H, Newman TA, Shepherd D, et al. Abeta exacerbates the neuronal dysfunction caused by human tau expression in a Drosophila model of Alzheimer's disease. Exp Neurol. 2010;223:401-9.

68. Roberson ED, Scearce-Levie K, Palop JJ, Yan F, Cheng IH, Wu T, et al. Reducing endogenous tau ameliorates amyloid beta-induced deficits in an Alzheimer's disease mouse model. Science. 2007;316:750-4.

69. Ittner LM, Ke YD, Delerue F, Bi M, Gladbach A, van Eersel J, et al. Dendritic function of tau mediates amyloid-beta toxicity in Alzheimer's disease mouse models. Cell. 2010;142:387-97.

70. Morris M, Koyama A, Masliah E, Mucke L. Tau reduction does not prevent motor deficits in two mouse models of Parkinson's disease. PLoS One. 2011;6:e29257.

71. Clinton LK, Blurton-Jones M, Myczek K, Trojanowski JQ, LaFerla FM. Synergistic interactions between Abeta, tau, and alpha-synuclein: acceleration of neuropathology and cognitive decline. J Neurosci. 2010;30:7281-9.

72. Emmer KL, Covy JP, Giasson Bl. Studies of protein aggregation in A53T alpha-synuclein transgenic, Tg2576 transgenic, and P246L presenilin-1 knock-in cross bred mice. Neurosci Lett. 2012;507:137-42.

73. Larson ME, Sherman MA, Greimel S, Kuskowski M, Schneider JA, Bennett DA, et al. Soluble alpha-synuclein is a novel modulator of Alzheimer's disease pathophysiology. J Neurosci. 2012;32:10253-66.

74. Guo JL, Covell DJ, Daniels JP, Iba M, Stieber A, Zhang B, et al. Distinct alpha-synuclein strains differentially promote tau inclusions in neurons. Cell. 2013;154:103-17.

75. Wang JW, Brent JR, Tomlinson A, Shneider NA, MCCabe BD. The ALSassociated proteins FUS and TDP-43 function together to affect Drosophila locomotion and life span. J Clin Invest. 2011;121:4118-26.

76. Lanson Jr NA, Maltare A, King H, Smith R, Kim JH, Taylor JP, et al. A Drosophila model of FUS-related neurodegeneration reveals genetic interaction between FUS and TDP-43. Hum Mol Genet. 2011;20:2510-23.

77. Masliah E, Rockenstein E, Inglis C, Adame A, Bett C, Lucero M, et al. Prion infection promotes extensive accumulation of alpha-synuclein in aged human alpha-synuclein transgenic mice. Prion. 2012;6:184-90.

78. Clippinger AK, D'Alton S, Lin WL, Gendron TF, Howard J, Borchelt DR, et al. Robust cytoplasmic accumulation of phosphorylated TDP-43 in transgenic models of tauopathy. Acta Neuropathol. 2013;126:39-50.

79. Kikis EA, Gidalevitz T, Morimoto RI. Protein homeostasis in models of aging and age-related conformational disease. Adv Exp Med Biol. 2010;694:138-59.

80. Giasson BI, Lee VM, Trojanowski JQ. Interactions of amyloidogenic proteins. Neuromolecular Med. 2003;4:49-58. 
81. Xu G, Stevens Jr SM, Moore BD, McClung S, Borchelt DR. Cytosolic proteins lose solubility as amyloid deposits in a transgenic mouse model of Alzheimer-type amyloidosis. Hum Mol Genet. 2013;22:2765-74.

82. David DC, Ollikainen N, Trinidad JC, Cary MP, Burlingame AL, Kenyon C. Widespread protein aggregation as an inherent part of aging in C. elegans. PLoS Biol. 2010;8:e1000450.

83. Scherzer CR, Jensen RV, Gullans SR, Feany MB. Gene expression changes presage neurodegeneration in a Drosophila model of Parkinson's disease. Hum Mol Genet. 2003;12:2457-66.

84. Lim Y-A, Rhein V, Baysang G, Meier F, Poljak A, Raftery M, et al. Abeta and human amylin share a common toxicity pathway via mitochondrial dysfunction. Proteomics. 2010;10:1621-33. 